\title{
Comparative Evaluation of Activated Carbons Prepared by Thermo-Chemical Activation of Lignocellulosic Residues in Fixed Bed Column Studies
}

\author{
Cibele C. O. Alves, Marcus V. Faustino, Adriana S. Franca, and Leandro S. Oliveira
}

\begin{abstract}
This paper presents a comparative evaluation of two activated carbons produced from different lignocellulosic residues (spent coffee grounds and Raphanus Sativus press cake), as adsorbents for removal of phenol from aqueous solutions in fixed-bed column studies. Both the prepared adsorbents presented outstanding adsorption capacities when compared to other low-cost adsorbents presented in the literature. Breakthrough curves were produced and several breakthrough models were evaluated for adequate description of the adsorption process in the column, with the Dose-Response model presenting the best fit to the experimental data.
\end{abstract}

Index Terms-Adsorption, agricultural residues, fixed bed, phenol removal.

\section{INTRODUCTION}

Agricultural by-products and wastes are materials that are being evaluated as promising precursors for the production of low-cost activated carbons, given that they are renewable, locally available in large quantities and inexpensive [1]. Coffee is the most important agricultural product in Brazil, and this crop generates large amounts of solid residues, including spent coffee grounds (SC) [2]. Recent studies have demonstrated the potential of non-edible oils for biodiesel production, employing Raphanussativus L. seeds (RS) [3]. However, thisprocess generates an extensive amount of solid residues, e.g., pressed seed cakes. Both the previously mentioned solid residues present environmental problems in terms of adequate disposal, given their limited applications as animal feed, silage or energy source, thus reinforcing the need for alternative uses [2].

Phenol is the base structure unit of a variety of synthetic organic compounds. It usually enters water sources from various chemicals, pesticides, paper, pulp and dye manufacturing industries, wastewaters from industries such as gas, resin, tanning, textile, plastic, rubber, pharmaceutical and petroleum [4]. The appreciable solubility of this compound in water, combined with its high reactivity and resistance to

Manuscript received April 8, 2014; revised June 9, 2014. This work was supported by the following Brazilian Goverment Agencies: CNPq (Grant \#454776/2012-8 and 306139/2013-8) and FAPEMIG (Grant \# CEX APQ-04168-10 and PPM-00505-13).

Marcus V. Faustino is with Colégio Militar de Belo Horizonte, Brazil (e-mail: marcusfaustino@yahoo.com.br).

Cibele C. O. Alves, Adriana S. Franca and Leandro S. Oliveira are with DEMEC, Universidade Federal de Minas Gerais, Av. Antônio Carlos 6627, Belo Horizonte, MG, 31270-901, Brazil (e-mail: cibeleoliveiraalves@gmail.com, adriana@demec.ufmg.br, leandro@demec.ufmg.br). biodegradation, make it an important toxic material listed as a priority pollutant to be monitored in the aquatic environment [5]. Adsorption using activated carbon (AC) has proved to be very effective in treating effluents and has been cited by the United States Environmental Protect Agency (EPA) as being one of the best available environmental control technologies [6]. However, the widespread use of AC adsorption is restricted because of the high cost of conventional and commercial carbons. Therefore, in recent years, many researchers have tried to produce ACs using renewable and cheaper precursors which are mainly industrial and agricultural by-products (lignocellulosics) [1], [7], [8].

In a previous study [1] we evaluated the aforementioned lignocellulosic residues, spent coffee grounds and Raphanussativus $L$. seeds pressed cake, in the preparation of activated carbons by thermo-chemical activation. The produced ACspresented adsorption capacities that were similar or even higher than those of commercial ACs and other residue-based adsorbents, and were found to be adequate for phenol removal in batch studies. However, given that adsorption processes for purification of wastewaters can be carried out either discontinuously, in batch reactors, or continuously, in fixed-bed columns, the performance of the adsorbents was herein further evaluated in column tests.

\section{MethodolOGY}

\section{A. Adsorbent Preparation}

The raw materials were treated with phosphoric acid $85 \%$ ( $1.7 \mathrm{~mL}$ acid/g material) and submitted to $2 \mathrm{~h}$ carbonization in a muffle oven at $500^{\circ} \mathrm{C}$. Afterwards, the produced adsorbents were washed until $\mathrm{pH} 7$ to remove the excess acid. The solids were dried at $110^{\circ} \mathrm{C}$ for $12 \mathrm{~h}$ and ground to particle diameters ranging grom 0.15 to $0.43 \mathrm{~mm}$ [1]. The produced adsorbents are denominated: SC (based on spent coffee grounds) and RS (based on Raphanus sativus press cake). The surface morphology of the samples was examined using a scanning electron microscope (JEOL JSM-5510).

\section{B. Adsorption Tests}

Continuous flow adsorption experiments were conducted in a cylindrical stainless steel column $(2.5 \mathrm{~cm}$ internal diameter and $10 \mathrm{~cm}$ height). At the bottom of the column, a $0.5 \mathrm{~mm}$ stainless steel sieve was attached followed by glass wool. Known quantities of adsorbent $(12 \mathrm{~g})$ were placed into the column, yielding bed heights of 4.68 and $5.28 \mathrm{~cm}$ of adsorbent for SC and RC, respectively. Phenol solutions of known concentrations were pumped downward through the 
column bed. Samples were collected at the column outlet at different time intervals and were analyzed for phenol concentration by a UV-Vis spectrophotometer (Hitachi $\mathrm{U}-2010)$ at $269 \mathrm{~nm}$. The inlet concentration was varied from 300 to $500 \mathrm{mg} / \mathrm{L}$ at a flow rate of $33.3 \mathrm{~mL} / \mathrm{min}$.

Phenol adsorption mechanism was evaluated in terms of fitting classical mathematic models. Model selection was based on highest $R^{2}$ values coupled with the lowest difference between calculated and experimental $C / C_{i}$ (y) values, evaluated according to the following root mean square error measure:

$$
R M S=\sqrt{\sum\left[\left(y_{, e s t}-y_{, \exp }\right) / q_{e, \exp }\right]^{2}} / N
$$

where $y_{\text {,exp }}$ and $y_{\text {,est }}$ are the experimental and calculated equilibrium adsorbent amounts, respectively, and $N$ corresponds to the number of experimental isotherm points.
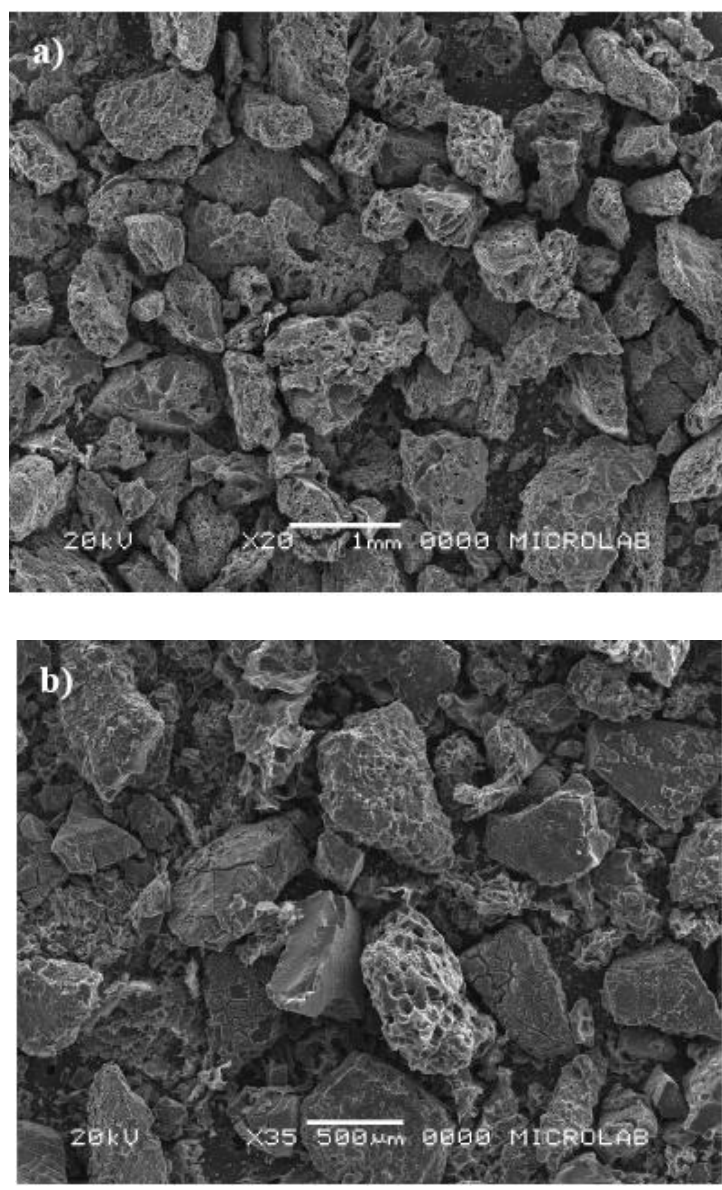

Fig. 1. Scanning electron micrograph (SEM) of activated carbons: a) SC based on spent coffee grounds and b) RC - based on raphanussativus pressed cake.

\section{RESULTS AND DISCUSSION}

\section{A. Adsorbent Characterization}

SEM images of the prepared activated carbons are shown in Fig. 1. It can be seen from the micrographs that the produced adsorbents present different pore sizes, and it seems that RS is more microporous. These results are in agreement with iodine number results from our previous study [1]. The iodine number (IN) can be directly correlated to the micropore volume, since the micropores are accessed preferentially by the iodine molecules due to their size. IN values were $25 \%$ higher for RS in comparison to SC [1].

\section{B. Adsorption Tests}

The effects of adsorb ate solution inlet concentrations on a fixed bed of adsorbents are presented in the breakthrough curves depicted in Fig. 2. Notice from Fig. 2 that the breakthrough curves do not follow the ideal "S" shape profile that is characteristic of adsorb ates of small molecular sizes and also of adsorbents comprised of relatively small sized particles. Phenol is a substance considered of small molecular size when compared to other common pollutants that are commonly removed from aqueous solutions by adsorption onto activated carbon-type of materials. Thus, the explanation for the deviation from the ideal " $\mathrm{S}$ " shape profile in this case can be attributed both to the adsorbents particle sizes and to their respective texture characteristics (e.g., pore size). The intrinsic low porosity of the adsorbent particles seems to be introducing a rather high resistance to the adsorb ateintraparticle diffusion, which, in turn, allows for axial dispersion to dominate the process. Not only it explains the deviation from the $\mathrm{S}$-shaped profile, but also explains the rather short breakthrough times and rather steep mass transfer zones of the breakthrough curves for both the Sc and RC adsorbents. Notice that an increase in the inlet adsorb ate concentration did not significantly affect the breakthrough times. However, as expected, the slope of the mass transfer zone became steeper and the bed service time shortened with an increase in inlet concentration [9], [10].

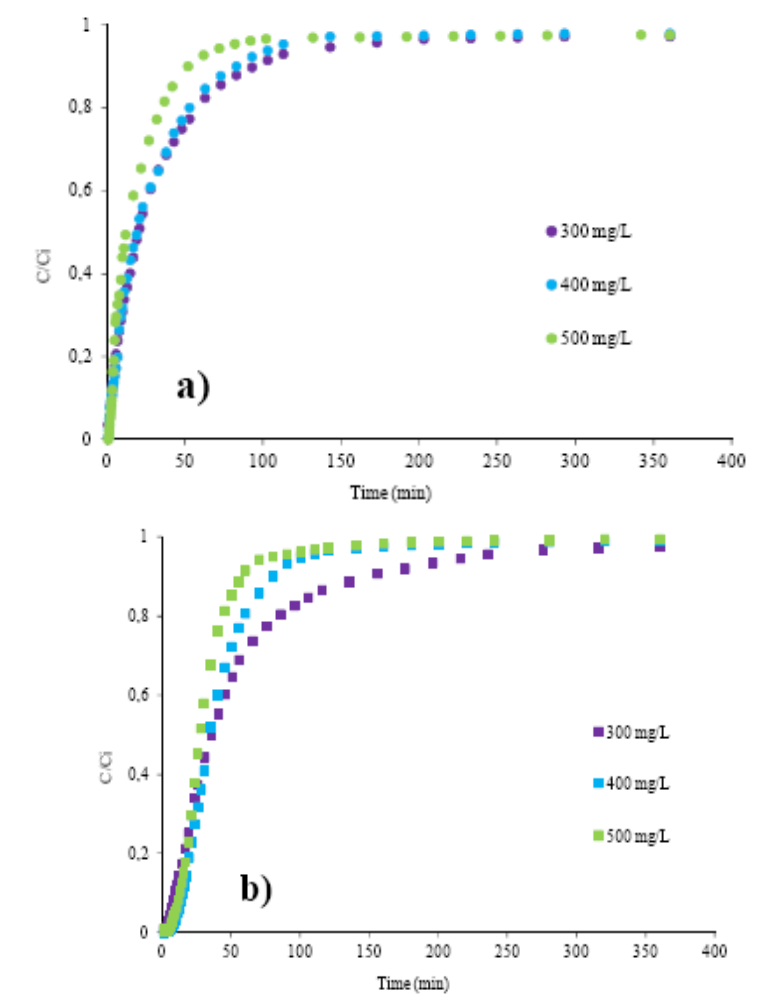

Fig. 2. Experimental breakthrough curves for the produced adsorbents at different values of inlet flow concentrations: a) SC - based on spent coffee grounds and b) RC - based on Raphanussativuspressed cake.

The differences in the curves in Fig. 2(a) and 2(b), not only can be explained by the differences in textural properties of 
the adsorbents and their respective beds (porosities of 0.39 and 0.44 for the SC and RC beds, respectively), but also by the difference in bed heights. Lower bed heights promote faster breakthrough times and steeper mass transfer zones, as it is clearly seen when the curves for the SC adsorbent are compared to those for the RC adsorbent, with the latter presenting a slightly deeper bed. Lower bed porosities will lead to higher resistance to antiparticle diffusion with consequent higher axial dispersion and faster breakthrough times.

Bohart-Adams, Yoon-Nelson, Thomas and Dose-Response breakthrough models were fitted to the experimental data and their respective parameters were estimated using nonlinear (Statistica 8.0 program) regressions. Details on estimated models kinetic parameters and the adsorption capacity are presented in Table I together with the respective experimentally determined values.

Bohart-Adams model [11] assumes that the adsorption rate is proportional to both the residual capacity of the solid and the concentration of the adsorbing species. It can be represented by the following equations:

$$
\begin{gathered}
\frac{C}{C_{i}}=\frac{\exp \left(K_{B A} C_{i} t\right)}{\exp \left(K_{B A} C_{i} t\right)+\exp \left(K_{B A} N_{o} z / U_{o}\right)-1} \\
q_{0}=N_{0} z S / m \\
\frac{C}{C_{i}}=1-\frac{1}{1+(Q t / b)^{a}} \\
q_{0}=\frac{C_{i} b}{m}
\end{gathered}
$$

where $C\left(\mathrm{mg} \mathrm{L}^{-1}\right)$ is the adsorbate concentration in the fluid at the column outlet at time $t(s), C_{i}\left(\mathrm{mg} \mathrm{L}^{-1}\right)$ is the adsorb ate concentration in the fluid at the inlet of the column, $N_{\mathrm{o}}\left(\mathrm{mg} \mathrm{L}^{-1}\right)$ is the sorption capacity per unit volume of fixed bed, $\mathrm{z}(\mathrm{cm})$ corresponds to bed depth, $U_{\mathrm{o}}\left(\mathrm{cm} \mathrm{min}{ }^{-1}\right)$ is the superficial velocity, $S\left(\mathrm{~cm}^{2}\right)$ is the bed cross section area, $m(\mathrm{~g})$ is the adsorbent mass and $\mathrm{q}_{0}$ is the adsorption capacity. As seen from the data presented in Table I, the rate constant $\left(k_{B A}\right)$ estimated from the nonlinear fitting of Bohart-Adams model does not vary significantly with variations in adsorbate inlet concentration, which means that the rate controlling mechanism is actually the adsorption kinetics rather than the mass transfer or the intraparticle diffusion. This was confirmed by the parameters obtained for both the Yoon-Nelson [12] and the Thomas [13] model fitting to the breakthrough data. These models presented the same fits, since all of them were developed under the assumption that adsorption kinetics is the controlling mechanism. Yoon and Nelson's model is based on the assumption that the probability of adsorption for each adsorb ate molecule decreases at a rate that is proportional to both the adsorb ate adsorption and adsorb ate breakthrough probabilities. It can be represented as [12]:

$$
\frac{C}{C_{i}}=\frac{1}{1+\exp \left[k_{Y N}\left(t_{50}-t\right)\right]}
$$

$$
q_{0}=\frac{C_{i} Q t_{50}}{m}
$$

where $t_{50}$ is the time required for $50 \%$ breakthrough and $Q(L$ $\mathrm{min}^{-1}$ ) is the volumetric flow rate through the column.

Thomas' model is frequently applied to estimate the adsorptive capacity of adsorbent and predict breakthrough curves, assuming second-order reversible reaction kinetics and Langmuir isotherm [14]. Theoretically, it is suitable to estimate the adsorption process where external and internal diffusion resistances are extremely small [15]. It can be represented by the following equation:

$$
\frac{C}{C_{i}}=\frac{1}{\left(1+\exp \left[\left(K_{T} / Q\right) \cdot\left(q_{o} \cdot m-C_{i} \cdot V_{e f}\right)\right]\right)}
$$

where $V_{e f}(L)$ is the volume of the effluent. According to the RMS values, it was observed that RC presented the best fits, which may be an indication that the chemical interactions in SC were more pronounced when compared to RS. Similar results were also found in batch experiments. The best fits for the RC adsorbent also corroborates the experimental observations that axial dispersion is less pronounced in that case when compared to the results for the SC adsorbent.

The best fit to the experimental data was presented by the Dose-Response model. This model was proposed for the description of heavy metal biosorption in columns [16]. It is has been recently employed in other studies and it is referred as being commonly used to describe different processes in pharmacology. It can be represented by the following equations:

$$
\begin{gathered}
\frac{C}{C_{i}}=1-\frac{1}{1+(Q t / b)^{a}} \\
q_{0}=\frac{C_{i} b}{m}
\end{gathered}
$$

Yan and his co-workers [16] observed that use of this model minimizes the error resulting from the use of the Thomas model, especially at lower or higher time periods of the breakthrough curve. However, the parameters in this model have no physical significance and hence cannot be evaluated accordingly.

The experimental fixed-bed adsorption capacities are presented in Table II, together with data for other adsorbents from the literature. The experimental fixed-bed adsorption capacities $\left(q_{0, \text { exp }}\right)$ were calculated according to equations:

$$
\begin{gathered}
q_{\mathrm{o}, \mathrm{exp}}=\frac{B C}{m} \\
B C=Q \int_{0}^{T}\left(C_{i}-C\right) d t
\end{gathered}
$$

where $B C$ is the bed capacity and represents the area below the breakthrough curve (mg), $G$ is the solution rate ( $\mathrm{L} / \mathrm{min}), C_{i}$ and $C$ are the inlet phenol concentration and outlet phenol 
concentration $(\mathrm{mg} / \mathrm{L})$ at time $t$, respectively, and $T$ is the actual time required for full bed exhaustion.

TABLE I: Bohart-AdAms, Yoon-Nelson, Thomas ANd Dose-Response Model PARAMETERS AT DifFerent AdSORBATE SOLUTION INLET CONCENTRATIONS

\begin{tabular}{|c|c|c|c|c|c|c|c|}
\hline \multirow{3}{*}{ Model } & \multirow{3}{*}{ Parameters } & \multicolumn{6}{|c|}{$C_{i}\left(\mathrm{mg} \mathrm{L}^{-1}\right)\left[Q=33.3 \mathrm{~mL} \mathrm{~min}^{-1}\right]$} \\
\hline & & \multicolumn{2}{|c|}{300} & \multicolumn{2}{|c|}{400} & \multicolumn{2}{|c|}{500} \\
\hline & & $\mathrm{SC}$ & RS & SC & $\mathrm{RS}$ & $\mathrm{SC}$ & RS \\
\hline \multirow{4}{*}{ Bohart-Adams } & $K_{B A} \times 10^{5}\left(\mathrm{~L} \mathrm{mg}^{-1} \mathrm{~min}^{-1}\right)$ & 23.504 & 19.929 & 19.192 & 22.997 & 20.892 & 25.297 \\
\hline & $q_{0}\left(\mathrm{mg} \mathrm{g}^{-1}\right)$ & 22.457 & 31.215 & 28.172 & 36.670 & 30.763 & 35.571 \\
\hline & $R^{2}$ & 0.954 & 0.960 & 0.958 & 0.989 & 0.977 & 0.993 \\
\hline & RMS & 0.083 & 0.343 & 0.242 & 0.586 & 0.151 & 0.268 \\
\hline \multirow{5}{*}{ Yoon-Nelson } & $K_{Y N}\left(\min ^{-1}\right)$ & 0.070 & 0.060 & 0.077 & 0.092 & 0.129 & 0.125 \\
\hline & $q_{0}\left(\mathrm{mg} \mathrm{g}^{-1}\right)$ & 20.376 & 33.778 & 25.737 & 40.629 & 29.139 & 39.510 \\
\hline & $t_{50}(\min )$ & 24.698 & 40.943 & 23.397 & 36.935 & 21.192 & 28.735 \\
\hline & $R^{2}$ & 0.954 & 0.960 & 0.956 & 0.989 & 0.977 & 0.993 \\
\hline & RMS & 0.161 & 0.506 & 0.438 & 0.957 & 0.306 & 0.472 \\
\hline \multirow{4}{*}{ Thomas } & $K_{T} \times 10^{5}\left(\min ^{-1}\right)$ & 23.717 & 19.891 & 18.201 & 22.866 & 20.465 & 24.919 \\
\hline & $q_{0}\left(\mathrm{mg} \mathrm{g}^{-1}\right)$ & 20.564 & 34.083 & 25.971 & 40.997 & 29.030 & 39.869 \\
\hline & $R^{2}$ & 0.954 & 0.960 & 0.956 & 0.990 & 0.977 & 0.993 \\
\hline & RMS & 0.164 & 0.517 & 0.444 & 0.985 & 0.311 & 0.487 \\
\hline \multirow{5}{*}{ Dose-Response } & $a(-)$ & 1.197 & 1.670 & 1.269 & 2.613 & 1.580 & 2.930 \\
\hline & $b(L)$ & 0.614 & 1.176 & 0.589 & 1.144 & 0.583 & 0.909 \\
\hline & $q_{0}\left(\mathrm{mg} \mathrm{g}^{-1}\right)$ & 15.371 & 29.416 & 19.652 & 38.140 & 24.325 & 37.885 \\
\hline & $R^{2}$ & 0.997 & 0.999 & 0.996 & 0.999 & 0.995 & 0.999 \\
\hline & RMS & 0.022 & 0.026 & 0.024 & 0.036 & 0.050 & 0.043 \\
\hline Experimental & $q_{0}\left(\mathrm{mg} \mathrm{g}^{-1}\right)$ & 16.611 & 18.435 & 22.544 & 31.550 & 26.269 & 34.675 \\
\hline
\end{tabular}

TABLE II: EXPERIMENTAL FIXED-BED AdSORPTION CAPACITIES $\left(Q_{0, E X P}\right)$ FOR PHENOL REMOVAL By AdSORBENTS BASEd ON AGRICULTURAL RESIDUES

\begin{tabular}{cccccc}
\hline \hline $\begin{array}{c}\text { Precursor } \\
\text { material }\end{array}$ & $\begin{array}{c}\mathrm{m} \\
(\mathrm{g})\end{array}$ & $\begin{array}{c}C_{0} \\
(\mathrm{mg} / \mathrm{L})\end{array}$ & $\begin{array}{c}Q \\
(\mathrm{~mL} / \mathrm{min})\end{array}$ & $\begin{array}{c}q_{0, \exp } \\
(\mathrm{mg} / \mathrm{g})\end{array}$ & Ref. \\
\hline \hline $\begin{array}{c}\text { Spent } \\
\text { coffee grounds }\end{array}$ & 12 & 500 & 33.3 & 27.65 & This study \\
$\begin{array}{c}\text { Raphanussativu } \\
s\end{array}$ & 12 & 500 & 33.3 & 34.67 & This study \\
$\begin{array}{c}\text { Sugarcane } \\
\text { bagasse }\end{array}$ & 5 & 20 & 33.3 & 12.02 & {$[17]$} \\
$\begin{array}{c}\text { Sugarcane } \\
\text { bagasse } \\
\text { Pinuspinaster } \\
\text { bark }\end{array}$ & 10 & 20 & 33.3 & 12.34 & {$[17]$} \\
\hline \hline
\end{tabular}

The adsorption capacity for the activated carbons (SC and $\mathrm{RS}$ ), in fixed bed adsorption process, can be considered significant when compared to capacity data for other low-cost adsorbents. Column adsorption capacity was lower in comparison to batch systems under the same initial phenol concentration, 40.1 and $39.7 \mathrm{mg} / \mathrm{g}$ for $\mathrm{SC}$ and $\mathrm{RC}$, reespectively [1]. The lower adsorption capacities observed in fixed bed systems in comparison to batch systems is usually attributed to the fact that the influent continuously meets a fresh part of adsorbent when it passes through the column and tends to establish a new equilibrium of adsorption, which is never attained, because the contact time in column systems is limited, thus reducing the adsorption capacity of adsorbents [19]. Also, a comparison between the experimentaly determined capacities and those calculated for each model demonstrates that the models consistently overestimated the fixed-bed adsorption capacities for both adsorbents, with the exception of the Dose-Response model fit of SC data. This can be explained by the fact that the assumptions made in the development of the models regarding adsorption mechanisms do not necessarily represent the actual mechanisms occurring during the experiments.

\section{CONCLUSIONS}

Fixed-bed column adsorption studies were conducted for the removal of phenol from aqueous solutions, using activated carbons prepared from spent coffee grounds and press-cake of Raphanussativus seeds as adsorbents. Both carbons were demonstrated to be adequate for such task and presented higher adsorption capacities for phenol than other low-cost adsorbents from the literature. Breakthrough models fitted well to the experimental data with the Dose-response model presenting a better fit than the others.

\section{ACKNOWLEDGMENT}

The authors are grateful to Prof. Sérgio F. Aquino and his 
co-workers at UFOP (Universidade Federal de OuroPreto) for their help with the SEM analyses.

\section{REFERENCES}

[1] C. C. O. Alves, P. D. Rocha, A. S. Franca, and L.S. Oliveira, "Preparation and characterization of activated carbons based on lignocellulosic residues," Advanced Materials Research, vol. 856, pp. 69-73, December 2013.

[2] A. S. Franca and L. S. Oliveira, "Coffee processing solid wastes: current uses and future perspectives," Agricultural Wastes, vol. 9, pp. 155-189.

[3] A. K. Domingos, E. B. Saad, H. M. Wilhelm, and L. P. Ramos, "Optimization of the ethanolysis of raphanussativus (L. Var.) crude oil applying the response surface methodology," Bioresource Technology, vol. 99, pp. 1837-1845, June 2008.

[4] P. Cañizares, M. Carmona, O. Baraza, A. Delgado, and M. A. Rodrigo, "Adsorption equilibrium of phenol onto chemically modified activated carbon F400,"Journal of Hazardous Materials, vol. 131, pp. 243-248, April 2006.

[5] B. Özkaya, "Adsorption and desorption of phenol on activated carbon and a comparison of isotherm models," Journal of Hazardous Materials, vol. 129, pp. 158-163, February 2006.

[6] R. Baccar, P. Blánquez, J. Bouzid, M. Feki, H. Attiya, and M. Sarrà, "Modeling of adsorption isotherms and kinetics of a tannery dye onto an activated carbon prepared from an agricultural by-product," Fuel Processing Technology, vol. 106, pp. 408-415, February 2013.

[7] M. Kilic, E. V. A. Varol, and A. E. Pütün, "Adsorptive removal of phenol from aqueous solutions on activated carbon prepared from tobacco residues: Equilibrium, kinetics and thermodynamics,' Journal of Hazardous Materials, vol. 189, pp. 397-403, May 2011.

[8] C. C. O. Alves, A. S. Franca, and L. S. Oliveira, "Removal of phenylalanine from aqueous solutions with thermo-chemically modified corn cobs as adsorbents," LWT - Food Science and Technology, vol. 51, pp. 1-8, April 2013.

[9] M. Goyal, M. Bhagat, and R. Dhawan, "Removal of mercury from water by fixed bed activated carbon columns," Journal of Hazardous Materials, vol. 171, pp. 1009-1015, November 2009.

[10] R. Han, Y. Wang, X. Zhao, Y. Wang, F. Xie, J. Cheng, and M. Tang, "Adsorption of methylene blue by phoenix tree leaf powder in a fixed-bed column: experiments and prediction of breakthrough curves," Desalination, vol. 245, pp. 284-297, September 2009.

[11] G. S. Bohart and E. Q. Adams, "Some aspects of the behavior of charcoal with respect to chlorine," Journal of the American Chemical Society, vol. 42, pp. 523-544, March 1920.

[12] Y. H. Yoon and J. H. Nelson, "Breakthrough time and adsorption capacity of respirator cartridges," American Industrial Hygiene Association Journal, vol. 45, pp. 509-516, May 1992.

[13] H.C. Thomas, "Heterogeneous ion exchange in a flowing system," Journal of the American Chemical Society, vol. 66, pp. 1664-1666, October 1994.

[14] K. H. Chu, "Fixed bed sorption: Setting the record straight on the Bohart-Adams and Thomas models," Journal of Hazardous Materials, vol. 177, p. 1006-1012, May 2010.

[15] M. Ghasemi, A. R. Keshtkar, R. Dabbagh, and S. J. Safdari, "Biosorption of uranium (VI) from aqueous solutions by Ca-pretreated Cystoseiraindica alga: Breakthrough curves studies and modeling," Journal of Hazardous Materials, vol. 189, pp.141-149, May 2011.

[16] G. Yan, T. Viraraghavan, and M. Chen, "A new model for heavy metal removal in a biosorption column," Adsorption Science \& Technology, vol. 19, pp. 25-43, February 2001.

[17] H. D. S. S. Karunarathne and B. M. W. P. K. Amarasinghe, "Fixed bed adsorption column studies for the removal of aqueous phenol from activated carbon prepared from sugarcane bagasse," Energy Procedia, vol. 34, pp. 83-90, 2013.

[18] G. Vázquez, R. Alonso, S. Freire, J. G. Álvarez, and G. Antorrena, "Uptake of phenol from aqueous solutions by adsorption in a
Pinuspinaster bark packed bed," Journal of Hazardous Materials, vol. 133, pp. 61-67, May 2006.

[19] A. S. Franca and L. S. Oliveira, "Fixed bed adsorption studies" in Sorption Processes and Pollution: Conventional and non-conventional sorbents for pollutant removal from wastewaters $\mathrm{G}$. Crini and P.-M. Badot, Ed. Besançon: Presses universitaires de Franche-Comté, 2010, pp. 79-112.

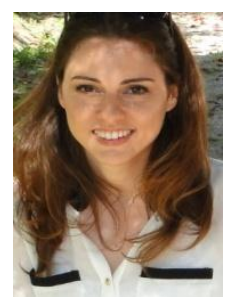

Cibele C. O. Alves was born in 1980. She was graduated in food engineering from Centro Universitário de Belo Horizonte, Brazil, in 2004. She completed her Ph.D. in food sciences from Universidade Federal de Minas Gerais, Belo Horizonte, Brazil, in 2009.

She worked as a post-doctoral fellow at Department of Mechanical Engineering at Universidade Federal de Minas Gerais, Belo Horizonte, Brazil, for the last couple of years. She has published 8 articles in international journals and has presented several research papers related to adsorption at various national and international conferences held in Brazil and abroad.

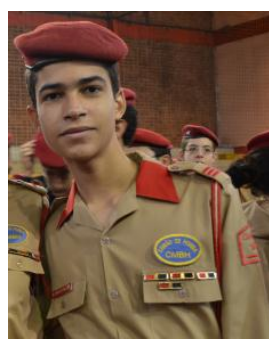

Marcus V. Faustino was born in 1997 and he is currently engaged in his second year of High School at Colégio Militar de Belo Horizonte. His work in this study resulted from his participation in a project at Universidade Federal de Minas Gerais, aiming at involving young students in research activities in engineering courses. The project was entitled "Engineering and sustainability: a multidisciplinary approach to the use of solid residues."

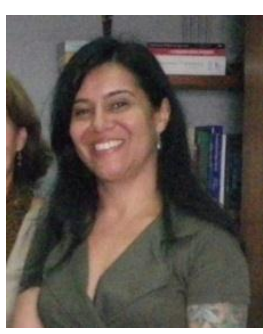

Adriana S. Franca was born in 1966. She was graduated in chemical engineering in 1988 and obtained her M.Sc. in mechanical engineering in 1991 from Universidade Federal de Minas Gerais, Belo Horizonte, Brazil. She completed her Ph.D. in agricultural and biological engineering from Purdue University, USA, in 1995.

She is currently working as an associate professor at the Department of Mechanical Engineering from Universidade Federal de Minas Gerais and also teahes a the graduate course in Food Sciences. She has published over 70 articles in international journals, 14 book chapters and has presented several research papers at various international conferences held in Brazil and abroad. Her research interests include sustainable uses of agricultural residues, coffee chemistry, microwaves, FTIR and others.

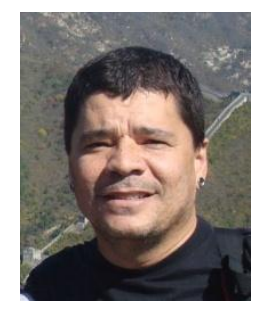

Leandro S. Oliveira was born in 1964. He graduated in chemical engineering in 1988 and obtained his M.Sc. in Mechanical Engineering in 1991 from Universidade Federal de Minas Gerais Belo Horizonte, Brazil. He completed his Ph.D. in agricultural and biological engineering from Purdue University, USA, in 1995.

He is currently working as an associate professor at the Department of Mechanical Engineering from Universidade Federal de Minas Gerais and is currently the head of the Graduate Program at that Department. Dr. Oliveira also teaches at the graduate course in Food Sciences.He has published 63 articles in international journals, 11 book chapters and has presented several research papers at various international conferences held in Brazil and abroad. His research interests include sustainable uses of solid residues, biofuels, coffee chemistry and others. 